\title{
THE IMPORTANCE OF BILINGUAL DESCRIPTION TO FOREIGN LANGUAGE LEARNING
}

\author{
GOLDIE PIROCH \\ University of Michigan
}

In the last fifteen years a sincere effort has been made to harness the results of structural linguistics to help the foreign language teacher. The results of this effort are frequently called the "new approach." According to Fries, "The fundamental feature of this new approach consists in a scientific descriptive analysis as the basis upon which to build the teaching materials." 1

Linguists were becoming increasingly interested in the spoken language, and so were the language teachers. Phonemics could help in the teaching of pronunciation. The phonemes of the native language were compared with those of the foreign language, with an eye out for potential trouble spots. But the possession of two inventories of phonemes was not the cureall of all pronunciation problems. ${ }^{2}$ The realization of this state of affairs is leading to increasing attempts to discuss the difficulties of the language learner when he meets a familiar sound in an unfamiliar environment or when the familiar sound enters into clusters in an unfamiliar way. Fries suggested in 1945:

"This determining of the distinctive sounds that differ is only the first step (although an important one) in the scientific comparison of the language to be learned with

\footnotetext{
${ }^{1}$ Charles C. Fries, Review of F. B. Agard and H. B. Dunkel. $A n$ Investitation of Second Language Teaching, Language Learning II (1949) p. 90.

${ }^{2}$ Yao Shen, "Some Departures from Strict Phonemic Representations, " Language Learning IV (1952-53) pp. 83-91.

Yao Shen, "Phonemic Charts Alone Are Not Enough," Language Learning, V (1955) pp. 122-129.

Einar Haugen, "Problems of Bilingual Description," Georgetown University Monograph Series on Languages and Linguistics, No. 7 (1954) pp. 919.
} 


\section{LANGUAGE LEARNING}

the native language of the learner. Each language has not only its own set of distinctive sound features; it also has only a limited number of characteristic sequences of consonants and vowels which make up the structural pattern of the syllables and words. From this fact arises the importance of finding the 'positions' in which the distinctive sounds can occur, and the 'clusters' which they may form." 3

For a foreshadowing of this point of view note also Henry Sweet in 1900:

"The first [consideration as regards phonetic difficulties ] is, that the difficulty of a sound depends more than anything on whether it is familiar or unfamiliar, which is not an intrinsic, but a relative or, we may almost say, an external difficulty. To the unphonetic learner all unfamiliar sounds are difficult, or even impossible-at least, he thinks so. This applies also to unfamiliar combinations of familiar sounds. Thus even initial (ts) may be difficult to English speakers, as well as such combinations as $\left.\left(\int \mathrm{t}\right\}\right)$ in Russian, because, although (ts) is a familiar combination, it is unfamiliar initial." 4

The comparison of not-necessarily-related linguistic structures has lately become a matter of interest also to linguists working in the field of bilingualism. Their goal is to describe what happens when two (or more) languages come in contact. To achieve this goal, Weinreich ${ }^{5}$ and Haugen ${ }^{6}$ have started to work on methods of setting up bilingual descriptions.?

\footnotetext{
${ }^{3}$ Charles C. Fries, Teaching and Learning English as a Foreign Language, Ann A rbor, 1945), p. 16.

${ }^{4}$ Henry Sweet, The Practical Study of Languages, (1900), pp. 61-62.

${ }^{5}$ Uriel Weinreich, languages in Contact, (New York, 1953).

${ }^{6}$ Einar Haugen, "Problems of Bilingual Description."

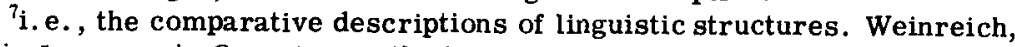
in Languages in Contact, uses the term "differential description"; Haugen, in a review of Weinreich's book, Language, XXX (1954), pp. 380-388, suggested the term "bilingual description." In an attempt to avoid the
} 
What these two authors have done represents a systematic treatment of phenomena of bilingualism which can be of further help to the foreign language teacher. It will be the purpose of this paper to briefly summarize the work done in bilingual description to date, and to illustrate the potential usefulness of this type of work with a partial bilingual description of English and Slovak from the point of view of the Slovak speaker learning English.

A brief outline of Weinreich's work along these lines, is found in the review of his Languages in Contact in the book review section of this issue.

Haugen, whose Norwegian Language in America: A Study in Bilingual Behavior appeared in the same year (1953), and whose book Bilingualism in the Americas: A Guide to Research is due to be published soon, also became interested in bilingual description. In his review of Weinreich's book, Haugen briefly mentions the importance of bilingual description "for the practical problems of teaching foreign languages." called "Problems of Bilingual Description," he shows how a bilingual phonemic descriptinn will involve the making of "comparisons of allophones position by position," and demonstrates how the types of interference can be summarized and systematized with the help of formulas. He maintains "that the identifications made between different phonemic systems by bilingual speakers can be predicted by careful bilingual description..." and "...that these can be tested by experimentation and observation, and can then be stated as diaphonic formulas in which the phonemes of the respective languages constitute the terms." 9 The relationship between the two parts of the formula he calls a diaphonic relationship, the members of the formula he calls diaphones of each other.

serious problem of using "bilingual" in too many senses (e.g., the speaker of more than one language, an inscription in two languages), I would prefer "dialinguistic description" which would be an extension of Haugen's use of "diaphone" and "diamorph."

${ }^{8}$ Haugen; Review of Weinreich Languages in Contact, Language XXX (1954), p. 381 .

${ }^{9}$ Haugen, "Problems of Bilingual Description," p. 19. For a more general discussion see also Kenneth L. Pike, Language in Relation to a Unified Theory of the Structure of Human Behavior, (Glendale, Calif. 1954), Section 2.6 "Predictability of Difficulties in Learning to React Emically to an Alien Emic System," pp. 18-19. 


\section{LANGUAGE LEARNING}

Let us now assume that we want to teach English to speakers of Slovak. (Translated into Weinreich's terms, the primary system is Slovak; the secondary, English.) In order to predict the interference we can make a bilingual description of English > Slovak,.$^{10}$ i.e., of how units in the structure of English will be identified with units in the structure of Slovak. We can test our results by using an informant.

First we need to find or to make a phonemic analysis of each language. ${ }^{11}$

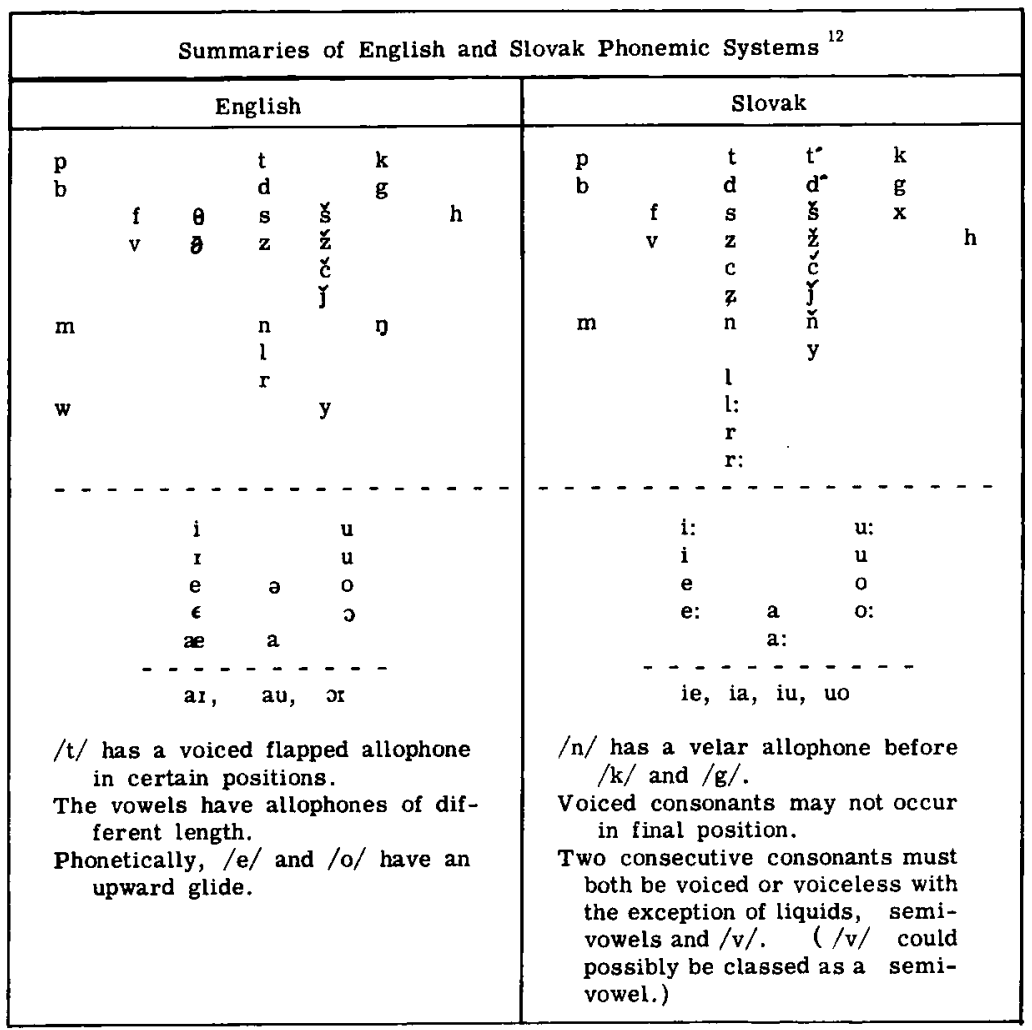

There is some objection to the $>$ on the basis that it implies time, but this is not really serious. In order that the Slovak speaker might identify one of his sounds with a sound in English, he will have had to 
With the help of adequately detailed analyses, each major allophone of each English phoneme is examined with careful attention to the limitations in its distribution, and attempts are made to predict with which Slovak phoneme it will be identified. The predictions are then plotted on charts like those below. ${ }^{13}$

hear the English sound first. Haugen uses the $>$ in his book Norwegian Language in America (U. of Pennsylvania Press, Philadelphia, Penna., 1953) to express loanwords, and later, in "Problems of $\mathrm{Bi}-$ lingual Description," he extends its use to bilingual description.

11 For a discussion of the theoretical problems involved in choosing one rather than another phonemic analysis see Haugen, "Problems of Bilingual Description," pp. 12-19.

12 The lists of the phonemes are complete. The comments are incomplete; they include only information pertinent to this paper, i.e. phonetic variants not used in the discussion below are intentionally omitted. The analysis of English is that used in Fries, Teaching and Learning English as a Foreign Language. It was chosen because it is an analysis of one dialect (one with which the writer is familiar), and because it is an analysis which is at present widely used in the teaching of English to foreign students. The analysis of Slovak is the writer's.

${ }^{13}$ Suggested by the charts in Henry M. Hoeningswald, "Diachronic Sound-Charts: A Technique to Represent Sound-Change," Studies in Linguistics, VI (1948) pp. 81-94. See also Einar Haugen, "A Note on Diachronic Sound Charts," SIL, VII (1949), pp. 63-66. 


\section{LANGUAGE LEARNING}

\begin{tabular}{|c|c|c|c|c|c|c|c|c|c|c|c|c|c|c|c|c|c|c|}
\hline \multicolumn{17}{|c|}{ Single Phonemes } & \multicolumn{2}{|c|}{$\begin{array}{c}\begin{array}{c}\text { Phoneme } \\
\text { Se- } \\
\text { quences }\end{array} \\
\end{array}$} \\
\hline$E^{S^{\prime}} \mathrm{p}$ & $\mathrm{b}$ & $\mathbf{t}$ & $\mathbf{k}$ & g & f & $\mathrm{v}$ & $\mathbf{s}$ & $z$ & $\mathbf{s}$ & है & $\mathrm{Y}$ & $\overrightarrow{\mathrm{h}}$ & $m$ & I & $y$ & n & nk & $\mathrm{ng}$ \\
\hline \begin{tabular}{l|l|}
$\mathbf{p}$ & $\infty$ \\
\end{tabular} & & & & & & & & & & & & & & & & & & \\
\hline b 04 & $\infty$ & & & & & & & & & & & & & & & & & \\
\hline$t$ & & $\infty \quad\left[t^{I}\right.$ & ] & & & & & & & & & & & & & & & \\
\hline d & & $0 \$ \infty$ & $\infty$ & & & & & & & & & & & & & & & \\
\hline o. & & 9 & & & & & & & & & & & & & & & & \\
\hline z) & & $0 \$ . \infty$ & $\infty$ & & & & & & & & & & & & & & & \\
\hline $\mathbf{k}$ & & & $\infty$ & & & & & & & & & & & & & & & \\
\hline $\mathrm{g}$ & & & 04 & $\infty$ & & & & & & & & & & & & & & \\
\hline $\mathrm{f}$ & & & & & $\mathbf{\infty}$ & & & & & & & & & & & & & \\
\hline$v$ & & & & & 0.9 & $\boldsymbol{\infty}$ & & & & & & & & & & & & \\
\hline$w$ & & & & & & $\omega$ & & & & & & & & & & & & \\
\hline$\dot{\mathbf{a}}$ & & & & & & & $\infty$ & & & & & & & & & & & \\
\hline $\mathbf{2}$ & & & & & & & 04 & $\infty$ & & & & & & & & & & \\
\hline$\check{s}$ & & & & & & & & $\infty$ & & & & & & & & & & \\
\hline $\mathbf{z}$ & & & & & & & & () & $\boldsymbol{\infty}$ & & & & & & & & & \\
\hline $\boldsymbol{c}$ & & & & & & & & & & $\mathbf{\infty}$ & & & & & & & & \\
\hline$\gamma$ & & & & & & & & & & 04 & $\infty$ & & & & & & & \\
\hline h & & & & & & & & & & & & $\infty$ & & & & & & \\
\hline $\mathbf{m}$ & & & & & & & & & & & & & $\mathbf{\infty}$ & & & & & \\
\hline 1 & & & & & & & & & & & & & & $\infty$ & & & & \\
\hline $\mathbf{r}$ & & & & & & & & & & & & & & $\infty$ & & & & \\
\hline $\mathrm{y}$ & & & & & & & & & & & & & & & $\infty$ & & & \\
\hline $\mathrm{n}$ & & & & & & & & & & & & & & & & $\infty$ & & \\
\hline D & & & & & & & & & & & & & & & & $(\mathbf{k g}$ & 04 & $\infty$ \\
\hline \multicolumn{19}{|c|}{$\begin{array}{l}\text { No English single phonemes will probably be identified with Slovak } / t^{*}, d^{*}, k, x, c, z / \text {, but } \\
\text { some English phoneme sequences not listed here are likely to be so identified. }\end{array}$} \\
\hline \multicolumn{12}{|c|}{ Single phonemes } & \multicolumn{7}{|c|}{ Phoneme Sequences } \\
\hline$E-S$ & i: & $\mathbf{i}$ & e & e: & a & a: & u & u: & o: & 0 & ou & ey & ay & a:y & $\mathrm{au}$ & a:u & oy & $0: y$ \\
\hline$i$ & {$[; \cdot]$} & $\infty$ & & & & & & & & & & & & & & & & \\
\hline $\mathbf{I}$ & & $\infty$ & & & & & & & & & & & & & & & & \\
\hline$\epsilon$ & & & $\infty$ & & & & & & & & & & & & & & & \\
\hline $\mathbf{a}$ & & & $\boldsymbol{\infty}$ & {$[\mathbf{z}]$} & & & & & & & & & & & & & & \\
\hline $\mathrm{a}$ & & & & & $\infty$ & [a] & & & & & & & & & & & & \\
\hline$\partial$ & & & & & $\phi$ & & & & & & & & & & & & & \\
\hline$v$ & & & & & & & $\boldsymbol{\infty}$ & & & & & & & & & & & \\
\hline $\mathbf{u}$ & & & & & & & & $\infty$ & & & & & & & & & & \\
\hline o & & & & & & & & & $\infty$ & & & & & & & & & \\
\hline 0 & & & & & & & & & {$[0]$} & $\infty$ & {$\left[\mathrm{ou}^{\mathrm{U}}\right]$} & & & & & & & \\
\hline e & & & & & & & & & & & & $\infty$ & & & & & & \\
\hline ar & & & & & & & & & & & & & $\infty$ & {$[\mathrm{a}+\mathrm{a}]$} & & & & \\
\hline 20 & & & & & & & & & & & & & & & $\infty$ & {$\left[p^{*} u\right]$} & & \\
\hline ox & & & & & & & & & & & & & & & & & $\mathbf{\infty}$ & {$\left[a^{\prime} D\right]$} \\
\hline
\end{tabular}


Read the above charts as follows: It can be predicted that English /p/ will be identified with Slovak /p/ in all environments. $/ \mathrm{b} /$ will be identified with $/ \mathrm{p} /$ before zero, with $\mathrm{s} / \mathrm{b} /$ in a $\mathrm{E}$ other environments. The $\mathrm{ftapped}$ allophone of $/ \mathrm{t} /$ will be identified with $\mathrm{S} / \mathrm{d} /$, the other allophones, with $\mathrm{E} / \mathrm{t} /$. $\mathrm{E}^{/ \mathrm{n} /}$ will be identified with $\mathrm{s} / \mathrm{n} /$ when occurring before $\mathrm{S} / \mathrm{k}$ / and $/ g /$, with $\mathrm{S} / \mathrm{nk} /$ when before zero, with ${ }_{\mathrm{r}} / \mathrm{ng} /$ elsewhere. (In indicating the language by the subscripts, I follow the usage of Weinreich.)

The charts presented here are incomplete, since they do not include such limitations on distribution as permitted consonant or vowel sequences. The charts could include these, but care would have to be taken to subdivide each of the charts into smaller, more manageable ones. An even better solution would be to make separate charts for vowel or consonant sequences. This, however, would not be particularly useful for Inglish > Slovak. (The comparison of the consonant sequences of these two languages will be discussed below.)

We can now systematize the data appearing on the charts, so that the interference can be summarized in diaphones. The following is the summary for the consonant systems:

\begin{tabular}{|c|c|c|c|}
\hline & $\begin{array}{c}\text { Weinreich's } \\
\text { classifications }\end{array}$ & $\begin{array}{l}\text { Diaphones according to } \\
\text { the Haugen system } 14\end{array}$ & Read as follows: \\
\hline 1. & phone substitution & $\begin{array}{l}\quad \text { simple diaphones } \\
\text { a. } \mathrm{E}^{/ \mathrm{h}>\mathrm{h} / \mathrm{s}} \\
\text { b. } \mathrm{E}^{/ \mathrm{m}>\mathrm{m} / \mathrm{s}} \\
\text { c. } \mathrm{E}^{/ 1}>1 / \mathrm{s} \\
\text { d. } \mathrm{E}^{/ \mathrm{r}}>\mathrm{r} / \mathrm{s} \\
\text { e. } \mathrm{E}^{/ \mathrm{y}>\mathrm{s}}\end{array}$ & $\begin{array}{l}\text { English } / \mathrm{h} / \text { is interpreted by } \\
\text { Slovak speakers as Slovak /h/ }\end{array}$ \\
\hline 2. & $\begin{array}{l}\text { over-differentiation } \\
\text { of phonemes }\end{array}$ & $\begin{array}{l}\text { compound divergent } \\
\text { diaphones } \\
\text { a. } E^{/ t>\mathrm{t} ; \mathrm{d} / \mathrm{s}} \\
\mathrm{b} \cdot \mathrm{E}^{/ \mathrm{n}>\mathrm{n} ; \mathrm{ng} / \mathrm{s}}\end{array}$ & $\begin{array}{l}\text { Some a ilophones of English } / t \text { / } \\
\text { are interpreted as Slovak } / t / \text {, } \\
\text { some as } / d \text { / }\end{array}$ \\
\hline \multirow[t]{2}{*}{3.} & \multirow[t]{2}{*}{$\begin{array}{l}\text { under-differentiation } \\
\text { of phonemes }\end{array}$} & $\begin{array}{l}\text { compound convergent } \\
\text { diaphones } \\
\text { a. } E^{/ \theta, t>t / s} \\
\text { b. } E^{\prime z, d>d / s} \\
\text { c. } E^{/ v, w>v / s}\end{array}$ & $\begin{array}{l}\text { English } / \theta / \text { and } / \mathrm{t} / \text { are both } \\
\text { interpreted as Slovak } / \mathrm{t} /\end{array}$ \\
\hline & & d. ${ }_{\mathrm{E}} / \mathrm{C}_{\mathrm{vl},}, \mathrm{C}_{\mathrm{vd}} \otimes>\mathrm{C}_{\mathrm{vl}} / \mathrm{S}$ & $\begin{array}{l}\text { All English voiceless consonants } \\
\text { and final voiced consonants are } \\
\text { interpreted as Slovak voiceless } \\
\text { consonants }\end{array}$ \\
\hline
\end{tabular}

${ }^{14}$ Patterns for these formulas representing diaphones are found in Haugen, "Problems of Bilingual Description," p. $12 \mathrm{ff}$. 


\section{LANGUAGE LEARNING}

Care must be taken to have only one phoneme on one side of the diaphone, otherwise the complexity of the formula could outweigh its usefulness. This may at times mean the setting up of more than one diaphone to cover all of the pertinent details. Notice, for instance, that diaphone $3 \mathrm{~d}$ adds information which was intentionally omitted from diaphones $3 b$ and $3 \mathrm{c}$; and that diaphones $2 \mathrm{a}$ and $3 \mathrm{a}$ supplement each other.

Before the diaphones are set up in final form they should be checked with more than one informant. If the phonemic systems of each language have been compared carefully, there should be little need for revision. For example, it might have been incorrectly predicted that the flapped allophone of the ${ }_{E} / t /$ would be identified with $S_{S} / r /$. In listening to a native ${ }^{E}$ Slovak speaking English, such a prediction would turn out to be incorrect and would send us back to recheck our bilingual description at that point. Presumably, as more people work in this field, it will be possible to eliminate errors of prediction.

Ideally, our informants should be people who do not yet speak English, or who are in the first stages of learning the second language. If we use informants who have been trying to use English for a longer period of time, it will seem that there are more exceptions to our predictions. Thus, if the informant says /styu/ instead of the expected /stu:/ for "stew," it is probable that the informant has actually heard the word so pronounced and has learned it in that way. If the informant does not consistently identify $\mathrm{E}^{/} / \mathrm{\partial} /$ with $\mathrm{S} / \mathrm{a} /$, as we predict he will do, it is important to check to what extent he has been influenced by English spelling.

If our primary goal in teaching a foreign language is not near-native perfection in pronunciation, but rather a pronunciation which avoids lexical misunderstanding, then not all of the three types of diaphones are equally relevant.

Phone substitution will not create problems in lexical understanding. Even though the phonetic realizations of $/ \mathrm{h} /$ are audibly different from $\mathrm{s} / \mathrm{h} /$, no misunderstanding $\mathrm{E}_{\text {will }}$ result when $s / h /$ is used in $S_{\text {English words. }}$

Over-differentiation of phonemes will also not be a problem. The Slovak speaker merely identifies allophones of an English phoneme as separate phonemes. Let us examine the 
two examples. The flapped allophone of $E^{/ t} /$ is identified with $_{S} / d /$. Since in English there is no contrast between $/ t /$ and $/ \mathbf{d} /$ in the position where the flapped allophone occurs (at least not in the dialect used in this paper, in which "bitter" and "bidder" have identical pronunciation), there will never be misunderstanding. $s / n /$ has a velar allophone before $s / k$ / and $S / g / ;$ English has only $/ \mathrm{g} /$ before $E^{/ k} /$ and $E^{/ g} /$. Though the phonemic interpretation is different, the phonetic result in this position is almost the same for the two languages. In other positions $\mathrm{s} / \mathrm{g} /$ is identified with $\mathrm{s} / \mathrm{ng} /($ or $\mathrm{s} / \mathrm{nk} /$ ). This again would cause no difficulty, since in English $/ \mathrm{n} /$ and $/ \mathrm{ng} /$ is a little used contrast.

Under-differentiation of phonemes is the real cause of serious pronunciation problems. If $E^{/ t} /$ and $E^{/ \theta / a r e ~ u n d e r-~}$ differentiated and both are identified with $S^{\mathrm{F}} /$, we will get ${ }_{E} /$ baet, bae $\theta>$ be:t $/ S$. If the voicing and voicelessness of final consonants is under-differentiated so that all final English consonants are identified with Slovak voiceless consonants we will further get $E^{/ b a e d, ~ b a e t ~>~ b e: t / ~} S$.

The predictions for the interference in vowels are a little more complex for these two languages. We can predict that English syllabic nuclei will be interpreted as long or short:

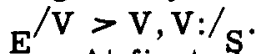

At first glance the two sets of descriptions of the vowels seem almost parallel in position, with the exception of an extra front vowel in English. Here, more than ever it is important to check the allophones, or phonetic realizations of the phonemes. In Slovak, for example, there is a difference in the height of the vowels/e, e:/, but there is also a difference in length. In the phonemicization, length is the distinctive feature. In the English vowels $/ \epsilon$, ae/, which correspond to this position, height is the distinctive feature. It can be predicted that $\mathrm{E} / \epsilon>\mathrm{e} / \mathrm{s}$ and $\mathrm{E}^{/ \mathrm{ae}}>\mathrm{e} / \mathrm{s}$. This, however, can be only partialty true. Trăger and $S$ mith ${ }^{15}$ most often give six allophones of different length for any given English syllabic. It can, therefore, be predicted that the longer allophones of the English vowel will be identified with a Slovak long vowel, and the shorter ones with a short vowel. For example, the

\footnotetext{
${ }^{15}$ George L. Trager and Henry Lee Smith, Jr., An Outline of English Structure, SIL Occasional Papers 3, 1951.
} 


\section{LANGUAGE LEARNING}

shorter allophones of $\mathrm{F} / \mathrm{ae} / \mathrm{as}$ in $/$ haet/ will also be identified with $s^{/ e /}$ while the longer ones, as in $E^{/ k a e n / ~ w i l l ~ b e ~}$ identified $\mathrm{with}_{\mathrm{S}} / \mathrm{e}$ /. The over-differentiation of $\mathrm{E} / \mathbf{a} /$ would by itself create no difficulty in understanding, except that it now produces an under-differentiation $-{ }_{E} / \epsilon$, ae $>\mathrm{e} / \mathrm{s}-$ and hence a problem. The two diaphones now are as follows:

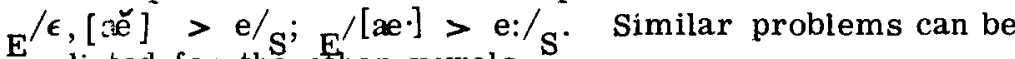
predicted for the other vowels.

The phonetic realization of $/ \mathrm{e} /$ will cause it to be identified with $/$ ey/ and hence no problem. It is probable that the more diphthongal allophones of $\mathrm{E}^{/ \mathrm{o} / \text { will be identified with }}$ /ou/. This will bring about an over-differentiation, but no problem.

The English diphthongs will probably be over-differentiated in that their first element will be identified sometimes with a long and sometimes with a short Slovak vowel. This again will entail no lexical misunderstanding.

The testing of the vowel diaphones with an informant, though it confirms most of these predictions, shows how very difficult it is to predict at which point on Trager and Smith's scale of length a vowel will be interpreted as long by a speaker of slovak. In other words, the informant does not automatically interpret the three shorter allophones of an English vowel as short, and the three longer ones as long. If the informant has had long contact with English, he will be consistent in choosing always a long, or always a short vowel for the same word.

Slovak and English both have many consonant sequences. A comparison of these in initial, medial and final positions gives the following predictions: 1 . The initial and medial sequences will give no difficulty except to the extent that the consonants in the sequence are under-differentiated. 2. Since all final consonants in Slovak must be voiceless, the pre-final consonants must follow the rules of Slovak consonant sequences as stated under the inventory of phonemes above. Thus we expect and get $\mathrm{E} / \mathrm{ragz}>\mathrm{raks} / \mathrm{S}, \mathrm{E} / \mathrm{bedz}>$ beyc/ $\mathrm{S}$ (Note that $\dot{\dot{C}} /-\partial z$ - -ts/ and is thus identified with $\mathrm{S} / \mathrm{c} /$ ). $\mathrm{S}_{3}$. In final position Slovak does not have any consonant sequences as long as $/$-mpst/. We can expect a shortening of the sequence. ${ }^{\mathrm{E}}$ Actually, we get ${ }_{\mathrm{E}} /$-mpst $>-\mathrm{mps} / \mathrm{S}$. 


\section{IMPORTANCE OF BILINGUAL DESCRIPTION}

A complete bilingual description would require that this phonemic part of the description be done in greater detail and that it be followed by a bilingual description of the two morphemic systems and of the positions in which morpheme classes occur ${ }^{6}$

Now that procedures for making bilingual descriptions are being more clearly defined, it is hoped that linguists and teachers trained in linguistics will contribute to the making of such descriptions. Contributions in this field will have both scientific interest and pedagogic usefulness.

\footnotetext{
${ }^{16}$ For a correlation on and above the morpheme level of French and English as well as German and English written utterances, see Rud $\mathbf{S}$. Meyerstein, "A Positional Determination of Semantic Equivalences in French, English and German," University of Michigan Doctoral Dissertation, 1955.
} 